\title{
Human telomerase activity regulation
}

\author{
Aneta Wojtyla $\cdot$ Marta Gladych $\cdot$ Blazej Rubis
}

Received: 16 July 2010/Accepted: 8 November 2010/Published online: 18 November 2010

(c) The Author(s) 2010. This article is published with open access at Springerlink.com

\begin{abstract}
Telomerase has been recognized as a relevant factor distinguishing cancer cells from normal cells. Thus, it has become a very promising target for anticancer therapy. The cell proliferative potential can be limited by replication end problem, due to telomeres shortening, which is overcome in cancer cells by telomerase activity or by alternative telomeres lengthening (ALT) mechanism. However, this multisubunit enzymatic complex can be regulated at various levels, including expression control but also other factors contributing to the enzyme phosphorylation status, assembling or complex subunits transport. Thus, we show that the telomerase expression targeting cannot be the only possibility to shorten telomeres and induce cell apoptosis. It is important especially since the transcription expression is not always correlated with the enzyme activity which might result in transcription modulation failure or a possibility for the gene therapy to be overcome. This review summarizes the current state of knowledge of numerous telomerase regulation mechanisms that take place after telomerase subunits coding genes transcription. Thus we show the possible mechanisms of telomerase activity regulation which might become attractive anticancer therapy targets.
\end{abstract}

Keywords Telomerase - Telomeres - Cancer . Telomerase activity regulation

\footnotetext{
A. Wojtyla · M. Gladych · B. Rubis ( $\square)$ Department of Clinical Chemistry and Molecular Diagnostics, Poznan University of Medical Sciences, Przybyszewskiego 49 St, 60-355 Poznan, Poland e-mail: blazejr@ump.edu.pl
}

\section{Introduction}

Telomeres, the guanine-rich repeated sequences located at the ends of chromosomes, function as a biological clock limiting the cell proliferation ability with every next cell division (Hayflick limit). However, most cancer cells reveal a telomere length maintenance mechanism (TMM) which is responsible for telomeres rebuilt that accompanies cellular proliferation [1]. Majority of cancer cells demonstrate the chromosome ends renewal mechanism involving telomerase, that utilizes its integral RNA molecule as a template for reverse transcription of new telomeric DNA. Other cell lines use a non-telomerase mechanism, known as Alternative Lengthening of Telomeres (ALT) which involves the use of a DNA template [2]. The telomere lengthening is either undetectable or has low level of activity in normal somatic cells while it is rather common in the vast majority of cancers [3, 4]. Thus it provides important target for detection and treatment of cancer cells.

Generally, the length of telomeres varies between 2 and $15 \mathrm{~kb}$ in germline cells [5, 6], whereas in human ALT cell lines, telomere length varies between 2 and over $50 \mathrm{~kb}$ $[7,8]$. The studies across many tumor types [9] have shown that the majority $(\sim 85 \%)$ of tumors express telomerase and hence are able to maintain a stable and homogenous telomere length and so avoid replicative senescence. The remaining $\sim 15 \%$ of tumors either do not maintain telomere length or they activate ALT [7]. For example almost $100 \%$ of adenocarcinomas express telomerase [10] whereas the ALT mechanism among the sarcomas is much more common i.e. $\sim 47 \%$ in osteosarcomas and $\sim 34 \%$ in astrocytomas [11], $\sim 25 \%$ in liposarcomas $[12,13]$. The reasons for the tissue difference in the utilization of telomerase or ALT is not understood but it has been proposed that telomerase (TERT expression) may be more heavily 
repressed in tissues of mesenchymal origin $[14,15]$. It is known that ALT positive primary tumors can give rise to telomerase-positive secondary tumors and vice versa [14]. Furthermore, there is evidence that both TMMs can be active in the same cell line and similarly that a small proportion of tumors express telomerase and markers for the ALT mechanism [12, 13]. There is the interest in targeting novel anticancer therapies at telomerase but tumors that utilize the ALT mechanism will not respond to such therapies. Thus quadruplex stabilizers appear to be the most promising strategies against ALT revealing cancers.

It was demonstrated in many studies that telomeres renewal is a multifactorial process in mammalian cells, involving telomerase gene expression, post-translational protein-protein interactions and protein phosphorylation (see Table 1). Numerous proto-oncogenes and tumor suppressor genes are also engaged in this mechanism and the complexity of telomerase control mechanisms is studied in the context of tumor development as well as ageing. Due to significant role of telomerase in those processes it is of great interest to identify the enzyme regulators. Additionally, since numerous studies reveal a correlation between short telomere length and increased mortality, the telomerase expression/activity appears to be one of the most crucial factors to study in order to improve the anticancer therapy and prevention. Thus, the enzyme seems to be the most promising target for therapy. However, because both, telomerase expression and activity, are not always correlated, targeting complex activity seems to be of great interest.

\section{Telomerase splicing variants}

Alternative mRNA splicing is a common mechanism that controls gene expression in higher eukaryotes and this process is known to be tissue-, development- and sex-specific [16]. The same phenomenon concerns TERT expression that can be alternatively spliced and different variants of that gene can be observed e.g. in testis and colonic crypt, suggesting complex regulation of this gene in the development [17-19].

\section{TERT}

As already reported, TERT splice variants may be expressed in normal, pre-crisis, and alternative lengthening of telomeres cells (ALT) that lack detectable telomerase activity [17-19]. Thus, transcriptional control of TERT is supposed to play the crucial role in the complex regulation of telomerase activity, however alternative splicing
Table 1 Human telomerase regulation factors

\begin{tabular}{|c|c|c|}
\hline Factor & $\begin{array}{l}\mathrm{Up}(\uparrow) / \text { down }(\downarrow) \\
\text { regulation }\end{array}$ & References \\
\hline \multicolumn{3}{|l|}{ Phosphorylation } \\
\hline Akt & $\uparrow$ & {$[60]$} \\
\hline Estrogen $^{\mathrm{a}}$ & $\uparrow$ & {$[120]$} \\
\hline Insulin-like growth factor I (IGFI) ${ }^{a}$ & $\uparrow$ & {$[65,122]$} \\
\hline Interleukin 6 (IL-6) ${ }^{\mathrm{a}}$ & $\uparrow$ & {$[66]$} \\
\hline Interleukin $2(\mathrm{IL}-2)^{\mathrm{a}}$ & $\uparrow$ & [125] \\
\hline PKC (izoforms $\alpha, \beta, \delta, \varepsilon, \zeta$ ) & $\uparrow$ & {$[66,68,70]$} \\
\hline Ionizing radiation $^{\mathrm{a}}$ & $\uparrow$ & [125] \\
\hline Ultraviolet irradiation $^{\mathrm{a}}$ & $\uparrow$ & [126] \\
\hline dimethyl sulfoxide (DMSO) $)^{\mathrm{a}}$ & $\uparrow$ & [126] \\
\hline Abl & $\downarrow$ & {$[55]$} \\
\hline $\mathrm{PP} 2 \mathrm{~A}$ & $\downarrow$ & [57] \\
\hline Imatinib mesylate (Gleevec) ${ }^{\mathrm{a}}$ & $\downarrow$ & {$[117]$} \\
\hline $\mathrm{PTEN}^{\mathrm{a}}$ & $\downarrow$ & [118] \\
\hline Gambogic acid ${ }^{\mathrm{a}}$ & $\downarrow$ & {$[62]$} \\
\hline Retinoic acid ${ }^{\mathrm{a}}$ & $\downarrow$ & [119] \\
\hline Mistletoe lectin ${ }^{a}$ & $\downarrow$ & {$[121]$} \\
\hline IP6 (inositol hexaphosphate) ${ }^{\mathrm{a}}$ & $\downarrow$ & {$[67]$} \\
\hline Oxygen $^{\mathrm{a}}$ & $\downarrow$ & {$[124]$} \\
\hline \multicolumn{3}{|l|}{ Transport } \\
\hline 14-3-3 signaling proteins & $\uparrow$ & [74] \\
\hline NF- $\kappa$ Bp65 & $\uparrow$ & [75] \\
\hline Shp-2 & $\uparrow$ & [76] \\
\hline Nucleolin & $\uparrow$ & {$[81]$} \\
\hline $\mathrm{H}_{2} \mathrm{O}_{2}^{\mathrm{a}}$ & $\downarrow$ & [77] \\
\hline Ran $(\text { GTPase })^{\mathrm{a}}$ & $\downarrow$ & [77] \\
\hline hPinX1 & $\downarrow$ & [80] \\
\hline \multicolumn{3}{|l|}{ Complex assembly } \\
\hline hnRNPA1 & $\uparrow$ & [98] \\
\hline TCAB1 & $\uparrow$ & [99] \\
\hline POT1 & $\uparrow$ & [104] \\
\hline TPP1 & $\uparrow$ & [104] \\
\hline TRF1, TRF2 & $\downarrow$ & [109] \\
\hline $\mathrm{Ku}$ & $\downarrow$ & [117] \\
\hline $\mathrm{hRap} 1^{\mathrm{a}}$ & $\downarrow$ & [113] \\
\hline
\end{tabular}

Arrows indicate activation $(\uparrow)$ or inhibition $(\downarrow)$ of telomerase activity

${ }^{\text {a }}$ Indirect influence on telomerase activity

variants are also suggested to play an important role in telomerase regulation. Ten different splice variants of TERT have been identified so far [17, 18, 20, 21]. The most relevant and widely studied variants involve splicing at two main sites: the $\alpha$ splice site and the $\beta$ site $[18,19]$. The $\alpha$ site deletion of 36 bp from exon 6 within reverse transcriptase (RT) motif A does not influence translation process $[17,22]$. The other deletions from exons 7 and 8 ( $\beta$ site, $182 \mathrm{bp}$ ) and one insertion (38 bp) cause premature 
translation terminations upstream of the essential RT motifs effectively deleting the remaining three reverse transcriptase motifs [23, 24]. Splicing at either site can occur independently or in combination to produce different full-length variants at different proportions within various cancer cell lines [25]. To date, only the $\alpha-/ \beta+$ variant has been shown to exhibit any regulatory function, acting as a dominant-negative inhibitor of telomerase activity when overexpressed in either normal or tumor cells $[25,26]$. These variants do not have catalytic activity since the RT motifs are required for this function [23, 24].

Another deletion variant of the TERT transcript was identified in hepatocellular carcinoma cell lines [20]. The deleted transcript was characterized by an in-frame deletion of $189 \mathrm{bp}$, spanning nucleotides 2710 to 2898, corresponding to the complete loss of exon 11 (gammadeletion). Interestingly, in gastric and hepatocellular carcinoma cell lines, the gamma deletion variant and its combination variants, $\alpha-$ and $\gamma-, \beta$ - and $\gamma-, \alpha-, \beta$ - and $\gamma$-deletion variants were frequently detected, while they were not detected in colorectal carcinoma cell lines [27].

The other three insertions occur downstream of the RT motifs and produce truncations of the protein. Since some C-terminal modifications have been shown to interfere with the ability of telomerase to maintain telomeres [28, 29], these insertion variants may not produce biologically functional proteins [25]. In the studies performed in osteosarcoma [30] it was concluded that in cell lines exhibiting full-length TERT mRNA/protein without any splice variants telomerase activity was higher than in cell lines expressing splice variants. It was also demonstrated that alternative splicing might be involved in controlling the telomerase activity in osteosarcoma cell lines, thereby contributing to the telomere maintenance mechanism. However, it is still unclear whether the ratio of full length to spliced TERT is important in determining telomerase activity [31]. In some studies it was shown that the absolute expression of TERT was well correlated with telomerase activity [32-35], while in other no correlation with either relative or absolute amounts of variant transcripts was revealed [36]. Thus, the regulatory function of various TERT transcripts is supposed to be cell type-specific, however, the many different methods used to quantify TERT mRNA in multiple studies [30, 36-46] made it difficult to standardize these findings [47]. It was also shown that the alternative splicing could be regulated by changes in the subcellular re-localization of splicing factors [48]. Accordingly, it was suggested that TERT could be regulated by TGF- $\beta 1$ through alternative splicing [38]. Alternatively, TGF- $\beta 1$ might induce rapid degradation of the TERT transcripts whereas c-Myc preferentially stabilizes the $\beta$ variant.

\section{Splicing variants of POT1}

It was shown that human POT1 protein (protection of telomeres, hPOT1) known to bind specifically to the G-rich telomere strand could act as a telomerase-dependent, positive regulator of telomere length [49]. In addition to full-length POT1 protein (variant v1), the human POT1 gene encodes four other variants due to alternative RNA splicing (variants v2, v3, v4, and v5), whose functions are poorly understood [50]. Importantly, a $\mathrm{COOH}$-terminally truncated variant (v5), which consists of the $\mathrm{NH} 2$-terminal oligonucleotide-binding $(\mathrm{OB})$ folds and the central region of unknown function, was found to protect telomeres and prevent cellular senescence as efficiently as v1. However, detailed mechanistic and functional differences between $\mathrm{v} 1$ and v5 were found [50] but their contribution to whole enzyme activity remains to be elucidated.

\section{Posttranslational regulation}

Transcriptional regulation is a crucial stage affecting telomerase activity, however, it has been well documented, that the regulation of the holoenzyme takes place during posttranslational mechanism and plays a pivotal role in modulating telomerase activity as well [51]. Posttranslational regulation of telomerase activity can occur via reversible phosphorylation of TERT catalytic subunit at specific serine/threonine or tyrosine residues [51]. Due to multiple kinase and phosphatase activators and inhibitors the telomerase phosphorylation status may affect its structure, localization and enzyme activity [51]. Numerous non-specific phosphorylation sites within TERT protein are postulated but only a few of them appear to be the key residues, and their phosphorylation influences telomerase activity (both, activation and inhibition) [52].

\section{Telomerase repression}

c-Abl

Specific phosphorylation site at TERT is present at prolinerich region (308-PSTSRPPRP-316) [51]. It was revealed that the contribution of c-Abl tyrosine kinase to TERT phosphorylation at specific tyrosine residue led to decreased telomerase activity. It was shown that overexpression of $c-A b l$ inhibited cell growth by causing cell cycle arrest [53]. Because of c-Abl's role in stress response to DNA damage, exposure of cells to ionizing radiation led to a significant increase in TERT phosphorylation by c-Abl [54]. It was also demonstrated that c-Abl phosphorylated TERT leading to inhibition of telomerase activity and 
decrease in telomere length [54] suggesting a direct association between $\mathrm{c}-\mathrm{Abl}$ and TERT. A crosstalk between Bcr$\mathrm{Abl}$ tyrosine kinase, protein kinase $\mathrm{C}$ and telomerase was also suggested as a potential reason for resistance to Glivec in chronic myelogenous leukemia [55].

\section{PP2A}

Protein phosphatase 2A (PP2A), which is engaged in the negative control of cell growth and division, reveals inhibitory function on telomerase activity in human breast cancer, PMC42 cells. As reported, PP2A remarkably abolished telomerase activity in nucleus while this effect was not observed when the other main cellular protein phospatases 1 and 2B were applied [56]. When active, PP2A dephosporylates TERT protein on Ser and/or Thr residue [57]. Another study showed that PP2A caused dephosphorylation of Akt kinase on Ser and/or Thr residue and thus abolished its activatory effect on TERT. However, it is still unclear if PP2A might directly dephosphorylate TERT without protein-protein interaction [58]. The effect of PP2A on TERT is blocked by its inhibitor, okadaic acid. Thus, endogenous protein kinase(s) might again phosphorylate telomerase catalytic subunit and reactivate the protein. It was then concluded that TERT phosphorylation and dephosphorylation was crucial to telomerase activity regulation in human breast cancer cells [56]. Another studies revealed that PP2A was a direct target for simian virus 40 , since this phosphatase is inhibited by viral oncogenic protein small-t antigen binding and consequently, the cell proliferation is stimulated. These data suggested the mechanism of telomerase activation and tumor genesis by oncogenic viruses [59]. Thus, pharmacological stimulation of PP2A dephosphorylation of telomerase in cancer may be of potential therapeutic significance.

\section{Telomerase activation}

\section{PKB}

The Akt kinase (known also as protein kinase B) shows a specificity to serine/threonine residues and enhances human telomerase activity through TERT phosphorylation. This explains Akt kinase's role in protecting cell from apoptosis and augmenting the cell proliferation capacity. It was shown in melanoma cells, that Akt kinase carried out this modification on serine residue at position 824 of TERT protein [60]. Phosphorylation at two different sites is necessary to activate Akt kinase (Ser473 and Thr308) [61]. However, some studies showed that Akt phosphorylation at serine 473 residue influenced subsequent phosphorylation of the TERT subunit. The authors also showed that Akt submitted to dephosphorylation at Ser473 by gambogic acid (GA, a natural antitumor compound) caused a decrease in TERT phosphorylation through Akt and subsequently decreased telomerase activity. Thus, Akt was suggested to be a limiting factor for human telomerase activity, especially since it plays a crucial role in human telomerase activity regulation through TERT phosphorylation at $\mathrm{PI} 3 \mathrm{~K} / \mathrm{Akt} / \mathrm{mTOR}$ pathway-dependent posttranscriptional level [62].

In physiological conditions down-regulation of telomerase activity takes place during differentiation of $\mathrm{CD} 8+\mathrm{T}$ cells since it is crucial to maintain the replicative capacity of memory T cells. However, CD8+ T cells may lose their ability to phosphorylate Akt kinase during gradual differentiation. Telomerase down-regulation in highly differentiated CD8+CD28-CD27- $\mathrm{T}$ cells leads to inevitable replicative end stage after their activation [63]. It was shown that TERT was associated with both, Akt and the heat shock protein HSP90 in human embryonic kidney and endothelial cells. This association is necessary for telomerase activity by Ser473 phosphorylation of its catalytic subunit while HSP90 prevents Akt kinase dephosphorylation (inactivation) by protein phosphatase $2 \mathrm{~A}(\mathrm{PP} 2 \mathrm{~A})$ and consequently decrease of telomerase activity [59]. Another study demonstrated that novobiocin (competitive inhibitor of HSP90) [64] inhibited formation of the Akt and Hsp90 complex and resulted in dephosphorylation and inactivation of Akt [58]. Additionally, it was shown that the proliferative and survival factors for human multiple myeloma (MM) cells, i.e. interleukin 6 (IL-6) and insulin-like growth factor 1 (IGF-1) up-regulated telomerase activity without alteration of human telomerase reverse transcriptase (TERT) protein expression [65]. As reported, that increase of telomerase activity caused by these cytokines was mediated by phosphatidylinositol 3'-kinase (PI3k)/Akt/ nuclear factor $\kappa \mathrm{B}(\mathrm{NF} \kappa \mathrm{B})$ signaling. Thus telomerase activity was shown to be related not only to transcriptional regulation of TERT by $\mathrm{NF} \kappa \mathrm{B}$ but also to posttranscriptional regulation because of phosphorylation of TERT by Akt kinase. These studies therefore demonstrated that telomerase activity was associated with cell growth, survival, and drug resistance in MM cells.

\section{PKC}

First studies of PKC (protein kinase C) in breast cancer cells showed that $\mathrm{PKC} \alpha$ phosphorylated both, TERT and human telomerase associated protein 1 (hTEP1) [66]. It was shown that inositol hexaphosphate (IP6) repressed telomerase activity via deactivation of $\mathrm{Akt}$ and $\mathrm{PKC} \alpha$ (Ser657) in prostate cancer cells [67]. Consequently, the lack of TERT phosphorylation makes impossible to bind its 
nuclear translocator and telomerase catalytic subunit is forced to go back from nucleus to cytoplasm. Thus, it was proposed that IP6 may also decrease the level of proteins involved in telomerase transport to the nucleus [67]. Other studies performed in human nasopharyngeal carcinoma (NPC) cells showed that telomerase activity is controlled by $\mathrm{PKC} \zeta$ isoform that phosphorylates TERT [68]. This kinase was postulated to be critical for phosphorylation of TERT (thus telomerase activation) during $\mathrm{T}$ cell activation as well. However, the participation of other PKC isoforms has not been excluded. The same author reported that in $\mathrm{T}$ lymphocytes the PKC activity was essential not only for post-transcriptional control of telomerase activity but also for induction of its expression through PKC-dependent signal pathway and induction of c-Myc expression [69]. The research on head and neck cancer cells revealed that expression of PKC isoenzymes $\alpha, \beta, \delta, \varepsilon$ and $\zeta$ and TERT phosphorylation was also correlated with higher telomerase activity in tumor cells [70].

\section{Transport}

When posttranslational modification are brought to an end, two main subunits of telomerase (TERT and TR) are delivered to the place of their action, nucleus.

\section{TERT nuclear transport}

In nonactivated CD4 $+\mathrm{T}$ cells telomerase activity is detected only in cytoplasm. However, in activated T cells, the TERT protein is present in both, cytoplasm and nucleus. Thus, total cellular amount of TERT remains constant-before and after activation, while transport of TERT from cytoplasm into nucleus takes place during $\mathrm{T}$ cells activation. Consequently, higher telomerase activity is observed in activated $\mathrm{T}$ cells which leads to telomere elongation in nucleus [71]. It is not clear yet whether TERT is transported into nucleus first, followed by telomerase complex assembly or if the whole telomerase complex is transferred into nucleus. Based on certain research, a hypothesis that TERT is transported into nucleus where telomerase complex is assembled seems to be more likely. It is supported by the fact that the vast majority of TR (human telomerase RNA) [72] as well as p23 and Hsp90 (telomerase complex components) are present in nucleus [73]. Several factors involved in TERT translocation into the nucleus has been identified. It was demonstrated that TERT binds to the 14-3-3 signaling proteins. This association is crucial for localization of TERT in the nucleus while it does not affect telomerase activity. The 14-3-3 proteins act as repressors of TERT after binding to a receptor for the nuclear export machinery (CRM1/exportin1) [74]. Another studies showed that TERT protein interacts directly with nuclear factor NF $\kappa$ B p65 in multiple myeloma cells which suggested that this factor modulated nuclear translocation of telomerase and played a crucial role in its regulation. Tumor necrosis factor $\alpha$ (TNF $\alpha$ ) activates NF $\kappa \mathrm{B}$ p65 that causes an increase in translocation of TERT bound to NF $\kappa \mathrm{B}$ p 65 from the cytoplasm to the nucleus. Moreover, this factor binds only phosphorylated TERT [75], thus other researchers concluded that Shp-2 (SH2-containing protein tyrosine phosphatase) might participate in the nuclear transport of TERT as well and suggested that Shp-2 is a negative regulator of Src mediated export. They also showed that in nucleus the Shp-2 was associated with TERT, but the complex dissociated just before TERT export. It was revealed that Shp-2 activity was significant for retaining TERT in the nucleus [76]. It was also shown that $\mathrm{H}_{2} \mathrm{O}_{2}$ treatment induced translocation of TERT from the nucleus into the cytoplasm. ROS-induced phosphorylation of tyrosine 707 within TERT is crucial for this nuclear export and Src kinase family is responsible for this modification. Nuclear export of TERT is a specific mechanism because it is connected with mitogenactivated protein kinase1/2 (MAPK1/2) import to the nucleus. When the TERT molecule is phosphorylated by Src kinase it binds with Ran (GTPase) that enables nuclear export of TERT via CRM1-related mechanism [77]. After TERT translocation from cytoplasm to nucleus the subsequent shuttling to the nucleolus (in normal cells) takes place [78]. However, in cancer cells, TERT protein is distributed mainly in nucleoplasm, where substrates for telomerase are present [79]. As reported, one of the nucleolar protein hPinX1 bound to TERT and therefore inhibited telomerase enzymatic activity [80]. Recent studies revealed that hPinX1 also increased the TERT transport from nucleoplasm to nucleolus. It was proposed that these two functions of hPinx 1 protein are independent from each other [79]. The other authors suggested that telomerase retaining in the nucleolus might prevent from interaction with its substrates present in nucleoplasm [78]. Despite binding of TERT with hPinX1, it can associate with TR and form a telomerase holoenzyme. This complex is stored in nucleolus where its function is kept dormant till cell division signal [78]. Nucleolin, a nucleolus protein, forms a complex with telomerase and facilitates the export of telomerase from nucleoli to the nucleoplasm. This process may involve masking of a nucleolar retention signal of TERT and/or nucleolin. It is supposed that nucleolin maintains telomerase in the nucleoplasm and therefore makes it ready for the delivery to the telomeres [81].

\section{TR nuclear transport}

As shown, translocation of TR and TERT is regulated and multiple nuclear structures participate in transport and 
biogenesis of telomerase [82]. Throughout most of the cell cycle TR is present in Cajal bodies that act as its transmitters to telomeres [83]. These subnuclear structures are general sites of RNP assembly and RNA modification [84]. In contrary to TR, TERT is located in distinct nucleoplasmic foci and thus, two main subunits of telomerase are separated during almost the whole cell cycle. In early $\mathrm{S}$ phase TERT is translocated to nucleoli. At the same time Cajal bodies containing TR accumulate at the periphery of nucleoli. Interestingly, TR accumulates at the pole of Cajal body that precedes localization to telomeres in mid-S phase when Cajal bodies deliver telomerase to individual telomeres. Furthermore, it was revealed that the same kinases and phosphatases that act during S-phase may modify telomerase subunits [82]. However, the mechanisms involved in targeting and accumulation of TR is not fully understood. To date, within telomerase RNA molecule the $\mathrm{CAB}$ box and H/ACA motif has been identified to influence the TR translocation to Cajal bodies and nucleoli [85, 86]. Analogically, one of TERT domain is known to mediate nucleolar translocation [87, 88].

\section{Telomerase complex assembly}

Human telomerase assembly occurs by complex mechanism consisted of few steps, depending on energy and involving first of all stabilization of TR and its subsequent association with TERT protein $[52,89]$. Only TERT protein and TR are necessary to gain telomerase activity in vitro. However, in vivo telomerase complex is composed of additional multiple proteins (see Fig. 1), that facilitate the enzyme to act [90]. Similarly to the transport of telomerase subunit TERT to the nucleus, assembly of the telomerase enzyme complex may be regulated during cell cycle. Telomerase assembly could take place during $\mathrm{S}$ phase and it is disassembled probably during $\mathrm{M}$ phase. Prevention of premature binding of the essential telomerase subunits (TERT and TR) is possible due to different sites of their compartmentalization and keeping them away from their substrates (telomeres) [82]. Thus, two telomerase assembling sites are possible during $\mathrm{S}$ phase i.e. at the telomere ends (similarly to yeast) [91] or in Cajal bodies [82]. It has been suggested that survival of motor neuron (SMN) complex, a RNP assembly factor present in Cajal bodies, takes part in telomerase biogenesis. It was demonstrated that TR is associated with GAR1, a protein which interacts with SMN complex [92]. However, it requires further analysis to establish where does the telomerase assembly occur. Recent studies showed that the localization of TR in Cajal bodies and near telomeres depends on TERT. This suggests that TR assembles a complex with TERT and then both proteins are transported to telomeres.

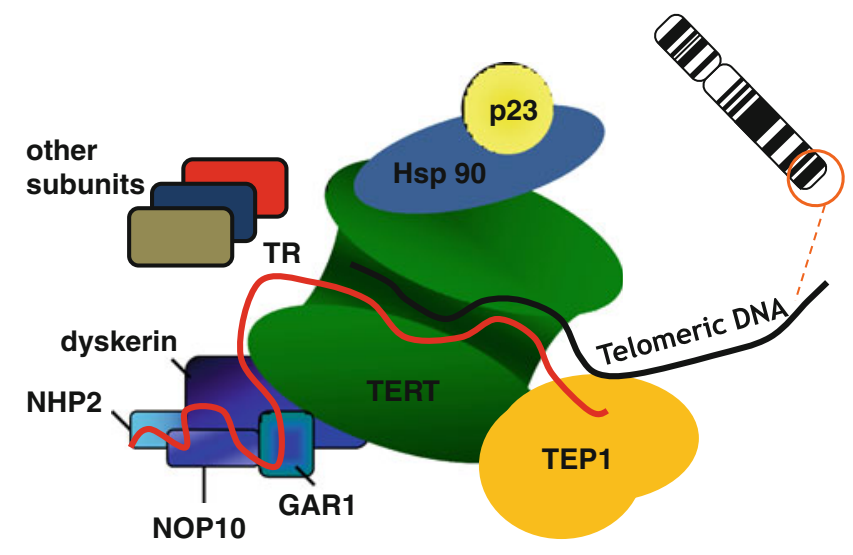

Fig. 1 Human telomerase complex. hTR, human telomerase RNA; hTERT, human Telomerase Reverse Transcriptase; Hsp90, heat shock protein 90; P23, the Hsp90-associated protein; TEP1, telomeraseassociated protein 1; dyskerin, NHP2, NOP10, GAR1, members of the H/ACA snoRNPs (small nucleolar ribonucleoproteins)

Alternatively, TERT is supposed to indirectly influence the trafficking of TR or a transient interaction of the two components that contribute to TR localization [93].

Telomerase RNA goes pseudourdylation by $\psi$ synthase dyskerin. This RNA modification is essential for assembly and stability of TR. Then, three additional H/ACA proteins bind: Nop10, Nhp2 and Gar1. Nop10 associates with Cbf5 (dyskerin homolog in yeast) which makes a core in TR complex. Association of other subunits (La, Staufen, L22 and hnRNP C1/C2, TEP1, p23 and Hsp90) enables stabilization and final structure formation [52, 73, 94]. However, the roles of these proteins in telomerase action is still unclear and further investigation is required.

ATPases and DNA helicases pontin and reptin reveal an essential role in telomerase assembly. The amount of TERT bound to pontin and reptin peaks in $\mathrm{S}$ phase [95]. When the two pivotal subunits of telomerase enzyme are stabilized and bound with auxiliary proteins the TERT and TR dimerization occurs. Two regions of TR are necessary for its binding with TERT: the template region (nucleotides 44-186) and a putative double hairpin element in the $5^{\prime}$ stem of the H/ACA domain, where TR stabilizing H/ACA proteins bind (nucleotides 243-326) [96].

Single-molecule fluorescence two-color coincidence detection technique (TCCD) made possible to show that active human telomerase comprises of TERT and TR in a 1:1 stoichiometry ratio [97]. When telomerase assemblage is finished, hnRNP A1 association with TR is required for holoenzyme access to telomeres. hnRNP A1 can bind simultaneously with TR and telomeric DNA and therefore acts as a potential link between telomerase enzyme and telomeres [98]. Recently, a novel protein TCAB1 (telomerase and Cajal body protein1) was isolated. This protein is a component of active telomerase and interacts with 
dyskerin. It is required for telomerase association both, with Cajal bodies (which deliver telomerase to chromosome ends) and with telomeres. Thus TCAB1 protein facilitates to elongate telomeres by telomerase [99].

\section{Telomeric proteins}

Beyond multiple levels of telomerase activity regulation presented in this review, an additional one exists. Interaction of telomerase with numerous telomere binding proteins (TBP) that may influence telomerase enzyme activity. It is supposed that binding some of them to telomeres and therefore making it impossible for telomerase to access the chromosome ends is an indirect way of telomerase activity regulation [51, 99].

A number of telomere binding proteins in human were identified [100, 101] and shown to play crucial role in telomere protection. They allow to distinguish telomeres from damaged DNAs by forming telomere structure with D and $\mathrm{T}$ loops and therefore prevent them from degradation and fusion. Shelterin, a very dynamic structure, is implicated in the generation of t-loops, and it controls the synthesis of telomeric DNA by telomerase. All six shelterin subunits (TRF1, TRF2, Rap1, TIN2, TPP1, POT1) can be found in a single complex in fractionated nuclear extracts [102, 103]. While shelterin complex seems to be responsible for negative telomerase regulation, the POT1-TPP1 proteins may activate telomerase processivity in certain conditions. Apparently, these two opposite functions of POT1-TPP1 complex seem to be impossible. However, it was proposed that POT1-TPP1 switches from inhibiting telomerase access to the telomere, as a component of shelterin, to serving as a processivity factor for telomerase during telomere extension. Three-state model of telomere length regulation was worked out [104]. At first state POT1 is directly bound at the $3^{\prime}$ end of telomere and associates with TPP1. This POT1-TPP1 position prevents binding of telomerase to chromosome ends [100]. TPP1-POT1 association enhanced POT1 affinity for telomeric ssDNA and TPP1 associates with the telomerase, providing a physical link between telomerase and the shelterin complex [105]. According to this model, these proteins are removed from their binding sites by an unidentified mechanism. Posttranslational modification or disruption of the shelterin might be involved in that process. At third state, released POT1-TPP1 complex may serve as an activator of telomerase during telomere extension. When elongated, telomere reaches a certain threshold, the newly synthesized repeats bind shelterin complexes and the 3 ' end of the overhang is re-bound by POT1-TPP1. This causes telomerase inhibition and return to the first state of the complex [105]. POT1 binds single stranded DNA at telomere end, but the number of RNA r(UUAGGGUUNG) sequences matching the POT1-binding site were identified [106]. Despite the possibility to bind with these RNAs, POT1 strongly binds only with telomeric DNA. Providing binding experiments with mixed DNA-RNA oligonucleotides and a high resolution crystal structure it was shown that a single ribouridine (rU4) instead of a deoxythymidine (dT4) in a telomeric sequence d(GGTTAGGGTTAG) is the primary determinant of RNA discrimination by hPOT1 [107]. However, other authors suppose that some of the POT1TPP1 complexes are not associated with single stranded DNA [108].

The TTAGGG repeat binding factor 1 and 2 (TRF1 and TRF2, respectively) are the main proteins responsible for negative feedback control in mammals. They are bound to double stranded DNA at T-loop, which is a "closed" state of telomere in which the telomerase enzyme cannot access and therefore extends the telomere terminus. TRF1 and TRF2 act as a negative regulators of telomeres length because they are involved in T-loop formation [109, 110]. TRF1 and TRF2 were shown to act in cis to repress telomere elongation. TRF1 was reported to repress the telomerase action on telomeres while, on the contrary, TRF2 appears to activate a telomeric degradation without showing any influence on telomerase [111]. Another proteins with the negative-feedback regulation of telomere length have been identified in human cells. The proteins acting on TRF1 are: Tankyrase 1 and 2 (TANK 1 and 2), TIN2, PINX1, three TRF1-interacting factors but also hRAP1 which interacts with TRF2 [111, 112]. PINX1 can inhibit telomerase by forming a stable complexes with catalytic subunit of telomerase and TRF1 molecule. It binds with TERT by its telomerase inhibitory domain (TID) placed at $\mathrm{C}$ terminal 74 aa [80]. The human repressor activator protein 1 (hRap1) was identified as a protein that specifically interacts with TRF2 and negatively regulates telomere length in vivo. It was shown that in addition to TRF2, the hRap1 forms a complex with a multiple DNA repair proteins: Rad50, Mre11, PARP1 (poly(ADP-ribose) polymerase), and $\mathrm{Ku} 86 / \mathrm{Ku} 70$ [113]. One of these $\mathrm{Ku}$ proteins has been proposed to be a direct regulator of human telomerase. It is a heterodimer of $\mathrm{Ku} 70$ and $\mathrm{Ku} 80$ (or $\mathrm{Ku} 86$ ) subunits and it is involved in DNA repair pathway. It was shown that $\mathrm{Ku}$ protein associated with human telomerase both, in vivo and in vitro [114]. It was reported that $\mathrm{Ku}$ associated with TERT and this interaction might regulate the access of telomerase to telomeres. It is possible that the association of telomerase with $\mathrm{Ku}$ might trap telomerase at the double-stranded region of telomeric DNA and this leads to decrease of the telomerase ability to access the exposed $3^{\prime}$ overhang [114]. On the contrary, other authors showed that human $\mathrm{Ku} 70 / 80$ associated with TR both, in vitro and in vivo. It was shown in TERT deficient cell lines 
not requiring the presence of telomerase catalytic subunit, which suggested that $\mathrm{Ku}$ interacted directly with $\mathrm{TR}$ (with a region of 47 nucleotides in the $3^{\prime}$ end of TR precisely). Thus, $\mathrm{Ku}$ may promote telomere elongation either by recruiting TR to chromosome ends or by stabilizing TR/TERT complexes once they form at the ends [115]. Therefore, it has been proposed that hRap1 associated with TRF2 may indirectly regulate telomerase by recruitment or regulation of $\mathrm{Ku}$ protein [113]. Recently, a novel protein (MOV10 helicase) binding to G-strand of both single- and double-stranded telomeric DNA was identified. MOV10 undergoes expression in human testis and ovary and seems to be necessary to maintain telomerase activity in those tissues. It is proven that MOV10 associates with TERT and telomere and therefore probably takes part in the progression of telomere lengthening [116].

\section{Summary and conclusions}

Intensive studies of telomerase functioning in human cells gave new perspectives on the mechanism of senescence, stem cells and cancer therapy. The studies show that numerous enzymes are required for telomerase functioning that facilitate new approaches for inhibiting telomerase in treating cancer. Probably there are still numerous unrevealed proteins that contribute to regulation of such a dynamic complex. In conclusion, TERT expression is regulated at both, the transcriptional and post-transcriptional levels, and the alternative splicing of TERT is also involved in the control of telomerase activity. However, contradictive reports concern the correlation of telomere length with telomerase activity or TERT expression in different cells which might confirm the tissue-specificity of the regulatory mechanism. Since telomerase plays a very important role in telomeres maintaining and thus it is responsible for unlimited survival of cancer cell but also for stem cells resources it seems very important to study the enzyme in the context of anticancer therapy but also tissue regeneration and aging.

One of the most promising strategies against telomerase is RNA interference and antisense nucleotide which is already in the second and even third clinic phase study however, multiple side effects were observed which stopped the enthusiasm about this method generally. Thus, the study of telomerase activity regulation at the level of enzymatic complex activity seems to give an alternative. Anyway, it is still supposed to use both, activity and expression regulation methods, as adjuvant therapies similarly to G-quadruplex stabilization. Understanding of telomerase activity may then bring a new insight into many serious clinical problems that we have to face in aging society.
Acknowledgment The present review was supported by N N401 223534 research grant.

Conflict of interest The authors declare that there are no conflicts of interest, financial or otherwise.

Open Access This article is distributed under the terms of the Creative Commons Attribution Noncommercial License which permits any noncommercial use, distribution, and reproduction in any medium, provided the original author(s) and source are credited.

\section{References}

1. Henson JD, Reddel RR (2010) Assaying and investigating alternative lengthening of telomeres activity in human cells and cancers. FEBS Lett [Epub ahead of print]

2. Bryan TM, Reddel RR (1997) Telomere dynamics and telomerase activity in in vitro immortalised human cells. Eur J Cancer 33:767-773

3. Wu KJ, Grandori C, Amacker M et al (1999) Direct activation of TERT transcription by c-MYC. Nat Genet 21:220-224

4. Ryan KM, Birnie GD (1997) Cell-cycle progression is not essential for c-Myc to block differentiation. Oncogene 14:2835-2843

5. Allshire RC, Dempster M, Hastie ND (1989) Human telomeres contain at least three types of G-rich repeat distributed nonrandomly. Nucleic Acids Res 17:4611-4627

6. de Lange T, Shiue L, Myers RM, Cox DR, Naylor SL, Killery AM, Varmus HE (1990) Structure and variability of human chromosome ends. Mol Cell Biol 10:518-527

7. Bryan TM, Englezou A, Gupta J, Bacchetti S, Reddel RR (1995) Telomere elongation in immortal human cells without detectable telomerase activity. EMBO J 14:4240-4248

8. Park KH, Rha SY, Kim CH et al (1998) Telomerase activity and telomere lengths in various cell lines: changes of telomerase activity can be another method for chemosensitivity evaluation. Int J Oncol 13:489-495

9. Kim NW, Piatyszek MA, Prowse KR et al (1994) Specific association of human telomerase activity with immortal cells and cancer. Science 266:2011-2015

10. Kammori M, Kanauchi H, Nakamura K, Kawahara M, Weber TK, Mafune K, Kaminishi M, Takubo K (2002) Demonstration of human telomerase reverse transcriptase in human colorectal carcinomas by in situ hybridization. Int J Oncol 20:15-21

11. Henson JD, Hannay JA, McCarthy SW et al (2005) A robust assay for alternative lengthening of telomeres in tumors shows the significance of alternative lengthening of telomeres in sarcomas and astrocytomas. Clin Cancer Res 11:217-225

12. Johnson JE, Varkonyi RJ, Schwalm J, Cragle R, Klein-Szanto A, Patchefsky A, Cukierman E, von Mehren M, Broccoli D (2005) Multiple mechanisms of telomere maintenance exist in liposarcomas. Clin Cancer Res 11:5347-5355

13. Costa A, Daidone MG, Daprai L et al (2006) Telomere maintenance mechanisms in liposarcomas: association with histologic subtypes and disease progression. Cancer Res 66:8918-8924

14. Henson JD, Neumann AA, Yeager TR, Reddel RR (2002) Alternative lengthening of telomeres in mammalian cells. Oncogene 21:598-610

15. Serakinci N, Hoare SF, Kassem M, Atkinson SP, Keith WN (2006) Telomerase promoter reprogramming and interaction with general transcription factors in the human mesenchymal stem cell. Regen Med 1:125-131 
16. Adams AK, Holm C (1996) Specific DNA replication mutations affect telomere length in Saccharomyces cerevisiae. Mol Cell Biol 16:4614-4620

17. Kilian A, Bowtell DD, Abud HE et al (1997) Isolation of a candidate human telomerase catalytic subunit gene, which reveals complex splicing patterns in different cell types. Hum Mol Genet 6:2011-2019

18. Ulaner GA, Hu JF, Vu TH et al (1998) Telomerase activity in human development is regulated by human telomerase reverse transcriptase (hTERT) transcription and by alternate splicing of hTERT transcripts. Cancer Res 58:4168-4172

19. Ulaner GA, Hu JF, Vu TH et al (2000) Regulation of telomerase by alternate splicing of human telomerase reverse transcriptase (hTERT) in normal and neoplastic ovary, endometrium and myometrium. Int J Cancer 85:330-335

20. Hisatomi H, Ohyashiki K, Ohyashiki JH et al (2003) Expression profile of a gamma-deletion variant of the human telomerase reverse transcriptase gene. Neoplasia 5:193-197

21. Saebøe-Larssen S, Fossberg E, Gaudernack G (2006) Characterization of novel alternative splicing sites in human telomerase reverse transcriptase (hTERT): analysis of expression and mutual correlation in mRNA isoforms from normal and tumour tissues. BMC Mol Biol 7:26

22. Wick M, Zubov D, Hagen G (1999) Genomic organisation and promoter characterization of the gene encoding the human telomerase reverse transcriptase (hTERT). Gene 232:97-106

23. Nakamura TM, Morin GB, Chapman KB et al (1997) Telomerase catalytic subunit homologs from fission yeast and human. Science 277:911-912

24. Lingner J, Hughes TR, Shevchenko A et al (1997) Reverse transcriptase motifs in the catalytic subunit of telomerase. Science 276:561-567

25. Yi X, White DM, Aisner DL et al (2000) An alternate splicing variant of the human telomerase catalytic subunit inhibits telomerase activity. Neoplasia 2:433-440

26. Colgin LM, Wilkinson C, Englezou A et al (2000) The hTERTalpha splice variant is a dominant negative inhibitor of telomerase activity. Neoplasia 2:426-432

27. Nagao K, Katsumata K, Aizawa Y et al (2004) Differential alternative splicing expressions of telomerase reverse transcriptase in gastrointestinal cell lines. Oncol Rep 11:127-131

28. Counter CM, Hahn WC, Wei W et al (1998) Dissociation among in vitro telomerase activity, telomere maintenance, and cellular immortalization. Proc Natl Acad Sci USA 95:14723-14728

29. Ouellette MM, Aisner DL, Savre-Train I et al (1999) Telomerase activity does not always imply telomere maintenance. Biochem Biophys Res Commun 254:795-803

30. Fujiwara-Akita H, Maesawa C, Honda T et al (2005) Expression of human telomerase reverse transcriptase splice variants is well correlated with low telomerase activity in osteosarcoma cell lines. Int J Oncol 26:1009-1016

31. Villa R, Porta CD, Folini M et al (2001) Possible regulation of telomerase activity by transcription and alternative splicing of telomerase reverse transcriptase in human melanoma. J Invest Dermatol 116:867-873

32. Kotoula V, Hytiroglou P, Pyrpasopoulou A et al (2002) Expression of human telomerase reverse transcriptase in regenerative and precancerous lesions of cirrhotic livers. Liver 22:57-69

33. Shimojima M, Komine F, Hisatomi H et al (2004) Detection of telomerase activity, telomerase RNA component, and telomerase reverse transcriptase in human hepatocellular carcinoma. Hepatol Res 29:31-38

34. Sun PM, Wei LH, Luo MY et al (2007) The telomerase activity and expression of hTERT gene can serve as indicators in the anti-cancer treatment of human ovarian cancer. Eur J Obstet Gynecol Reprod Biol 130:249-257

35. Satra M, Tsougos I, Papanikolaou V et al (2006) Correlation between radiation-induced telomerase activity and human telomerase reverse transcriptase mRNA expression in HeLa cells. Int J Radiat Biol 82:401-409

36. Barclay JY, Morris A, Nwokolo CU (2005) Telomerase, hTERT and splice variants in Barrett's oesophagus and oesophageal adenocarcinoma. Eur J Gastroenterol Hepatol 17:221-227

37. Krams M, Claviez A, Heidorn K et al (2001) Regulation of telomerase activity by alternate splicing of human telomerase reverse transcriptase mRNA in a subset of neuroblastomas. Am J Pathol 159:1925-1932

38. Cerezo A, Kalthoff H, Schuermann M et al (2002) Dual regulation of telomerase activity through c-Myc-dependent inhibition and alternative splicing of hTERT. J Cell Sci 115: $1305-1312$

39. Fajkus J, Borsky M, Kunická Z et al (2003) Changes in telomerase activity, expression and splicing in response to differentiation of normal and carcinoma colon cells. Anticancer Res 23:1605-1612

40. Fujiwara M, Kamma H, Wu W et al (2004) Expression and alternative splicing pattern of human telomerase reverse transcriptase in human lung cancer cells. Int J Oncol 24:925-930

41. Liu D, O'Connor MS, Qin J, Songyang Z (2004) Telosome, a mammalian telomere-associated complex formed by multiple telomeric proteins. J Biol Chem 279:51338-51342

42. Zaffaroni N, Villa R, Pastorino U et al (2005) Lack of telomerase activity in lung carcinoids is dependent on human telomerase reverse transcriptase transcription and alternative splicing and is associated with long telomeres. Clin Cancer Res 11:28322839

43. Brandt S, Heller H, Schuster KD, Grote J (2005) The tamoxifeninduced suppression of telomerase activity in the human hepatoblastoma cell line HepG2: a result of post-translational regulation. J Cancer Res Clin Oncol 131:120-128

44. Rha SY, Jeung HC, Yang WI et al (2006) Alteration of hTERT full-length variant expression level showed different gene expression profiles and genomic copy number changes in breast cancer. Oncol Rep 15:749-755

45. Mavrogiannou E, Strati A, Stathopoulou A et al (2007) Realtime RT-PCR quantification of human telomerase reverse transcriptase splice variants in tumor cell lines and non-small cell lung cancer. Clin Chem 53:53-61

46. Wang Y, Kowalski J, Tsai HL et al (2008) Differentiating alternative splice variant patterns of human telomerase reverse transcriptase in thyroid neoplasms. Thyroid 18:1055-1063

47. Lincz LF, Mudge LM, Scorgie FE et al (2008) Quantification of hTERT splice variants in melanoma by SYBR green real-time polymerase chain reaction indicates a negative regulatory role for the beta deletion variant. Neoplasia 10:1131-1137

48. van Oordt W, Diaz-Meco MT, Lozano J et al (2000) The $\operatorname{MKK}(3 / 6)$-p38-signaling cascade alters the subcellular distribution of hnRNP A1 and modulates alternative splicing regulation. J Cell Biol 149:307-316

49. Colgin LM, Baran K, Baumann P et al (2003) Human POT1 facilitates telomere elongation by telomerase. Curr Biol 13:942-946

50. Yang Q, Zhang R, Horikawa I et al (2007) Functional diversity of human protection of telomeres 1 isoforms in telomere protection and cellular senescence. Cancer Res 67:11677-11686

51. Cong YS, Wright WE, Shay JW (2002) Human telomerase and its regulation. Microbiol Mol Biol Rev 66:407-425

52. Aisner DL, Wright WE, Shay JW (2002) Telomerase regulation: not just flipping the switch. Curr Opin Genet Dev 12:80-85 
53. Sawyers CL, McLaughlin J, Goga A, Havlik M, Witte O (1994) The nuclear tyrosine kinase c-Abl negatively regulates cell growth. Cell 77:121-131

54. Kharbanda S, Kumar V, Dhar S et al (2000) Regulation of the hTERT telomerase catalytic subunit by the c-Abl tyrosine kinase. Curr Biol 10:568-575

55. Bakalova R, Ohba H, Zhelev Z, Ishikawa M, Shinohara Y, Baba Y (2003) Cross-talk between Bcr-Abl tyrosine kinase, protein kinase $\mathrm{C}$ and telomerase-a potential reason for resistance to Glivec in chronic myelogenous leukaemia. Biochem Pharmacol 66:1879-1884

56. Li H, Zhao LL, Funder JW, Liu JP (1997) Protein phosphatase $2 \mathrm{~A}$ inhibits nuclear telomerase activity in human breast cancer cells. J Biol Chem 272:16729-16732

57. Avci CB, Sahin F, Gunduz C et al (2007) Protein phosphatase 2A (PP2A) has a potential role in CAPE-induced apoptosis of CCRF-CEM cells via effecting human telomerase reverse transcriptase activity. Hematology 12:519-525

58. Haendeler J, Hoffmann J, Rahman S et al (2003) Regulation of telomerase activity and anti-apoptotic function by protein-protein interaction and phosphorylation. FEBS Lett 536:180-186

59. Janssens V, Goris J, Van Hoof C (2005) PP2A: the expected tumor suppressor. Curr Opin Genet Dev 15:34-41

60. Kang SS, Kwon T, Kwon DY, Do SI (1999) Akt protein kinase enhances human telomerase activity through phosphorylation of telomerase reverse transcriptase subunit. J Biol Chem 274:13085-13090

61. Jacinto E, Facchinetti V, Liu D et al (2006) SIN1/MIP1 maintains rictor-mTOR complex integrity and regulates Akt phosphorylation and substrate specificity. Cell 127:125-137

62. Zhao Q, Yang Y, Yu J et al (2008) Posttranscriptional regulation of the telomerase hTERT by gambogic acid in human gastric carcinoma 823 cells. Cancer Lett 262:223-231

63. Plunkett FJ, Franzese O, Finney HM et al (2007) The loss of telomerase activity in highly differentiated $\mathrm{CD} 8^{+} \mathrm{CD} 28^{-} \mathrm{CD} 27^{-}$ $\mathrm{T}$ cells is associated with decreased Akt (Ser473) phosphorylation. J Immunol 178:7710-7719

64. Marcu MG, Schulte TW, Neckers L (2000) Novobiocin and related coumarins and depletion of heat shock protein 90dependent signaling proteins. J NatlCancer Inst 92:242-248

65. Akiyama M, Hideshima T, Hayashi T et al (2002) Cytokines modulate telomerase activity in a human multiple myeloma cell line. Cancer Res 62:3876-3882

66. Li H, Zhao L, Yang Z et al (1998) Telomerase is controlled by protein kinase $\mathrm{C} \alpha$ in human breast cancer cells. J Biol Chem 273:33436-33442

67. Jagadeesh S, Banerjee PP (2006) Inositol hexaphosphate represses telomerase activity and translocates TERT from the nucleus in mouse and human prostate cancer cells via the deactivation of Akt and PKC $\alpha$. Biochem Biophys Res Commun 349:1361-1367

68. Yu CC, Lo SC, Wang TC (2001) Telomerase is regulated by protein kinase $\mathrm{C}-\zeta$ in human nasopharyngeal cancer cells. Biochem J 355:459-464

69. Sheng WY, Chien YL, Wang TC (2003) The dual role of protein kinase $\mathrm{C}$ in the regulation of telomerase activity in human lymphocytes. FEBS Lett 540:91-95

70. Chang JT, Lu YC, Chen YJ et al (2006) hTERT phosphorylation by $\mathrm{PKC}$ is essential for telomerase holoprotein integrity and enzyme activity in head neck cancer cells. $\mathrm{Br} \mathrm{J}$ Cancer 94:870-878

71. Liu K, Hodes RJ, Weng NP (2001) Telomerase activation in human $\mathrm{T}$ lymphocytes does not require increase in telomerase reverse transcriptase (hTERT) protein but is associated with hTERT phosphorylation and nuclear translocation. J Immunol $166: 4826-4830$
72. Hiyama E, Hiyama K, Yokoyama T, Shay JW (2001) Immunohistochemical detection of telomerase (hTERT) protein in human cancer tissues and a subset of cells in normal tissues. Neoplasia 3:17-26

73. Forsythe HL, Jarvis JL, Turner JW et al (2001) Stable association of Hsp90 and p23, but not Hsp70, with active human telomerase. J Biol Chem 276:15571-15574

74. Seimiya H, Sawada H, Muramatsu Y et al (2000) Involvement of 14-3-3 proteins in nuclear localization of telomerase. EMBO J 19:2652-2661

75. Akiyama M, Hideshima T, Hayashi $T$ et al (2003) Nuclear factor- $\kappa \mathrm{B}$ p65 mediates tumor necrosis factor $\alpha$-induced nuclear translocation of telomerase reverse transcriptase protein. Cancer Res 63:18-21

76. Jakob S, Schroeder P, Lukosz M et al (2008) Nuclear protein tyrosine phosphatase Shp-2 is one important negative regulator of nuclear export of telomerase reverse transcriptase. J Biol Chem 283:33155-33161

77. Haendeler J, Hoffmann J, Brandes RP et al (2003) Hydrogen peroxide triggers nuclear export of telomerase reverse transcriptase via Src kinase family-dependent phosphorylation of tyrosine 707. Mol Cell Biol 23:4598-4610

78. Wong JM, Kusdra L, Collins K (2002) Subnuclear shuttling of human telomerase induced by transformation and DNA damage. Nat Cell Biol 4:731-736

79. Lin J, Jin R, Zhang B, et al (2007) Characterization of a novel effect hPinX1 on hTERT nucleolar localization. Biochem Biophys Res Commun 353:946-952

80. Zhou XZ, Lu KP (2001) The Pin2/TRF1-interacting protein PinX1 is a potent telomerase inhibitor. Cell 107:347-359

81. Khurts S, Masutomi K, Delgermaa L, et al (2004) Nucleolin interacts with telomerase. J Biol Chem 279:51508-51515

82. Tomlinson RL, Ziegler TD, Supakorndej T et al (2006) Cell cycle-regulated trafficking of human telomerase to telomeres. Mol Biol Cell 17:955-965

83. Jády BE, Richard P, Bertrand E, Kiss T (2006) Cell cycledependent recruitment of telomerase RNA and Cajal bodies to human telomeres. Mol Biol Cell 17:944-954

84. Cioce M, Lamond AI (2005) Cajal bodies: a long history of discovery. Annu Rev Cell Dev Biol 21:105-131

85. Lukowiak AA, Narayanan A, Li ZH et al (2001) The snoRNA domain of vertebrate telomerase RNA functions to localize the RNA within the nucleus. RNA 7:1833-1844

86. Jády BE, Bertrand E, Kiss T (2004) Human telomerase RNA and box H/ACA scaRNAs share a common Cajal body-specific localization signal. J Cell Biol 164:647-652

87. Etheridge KT, Banik SS, Armbruster BN, et al (2002) The nucleolar localization domain of the catalytic subunit of human telomerase. J Biol Chem 277:24764-24770

88. Yang Y, Chen Y, Zhang C et al (2002) Nucleolar localization of hTERT protein is associated with telomerase function. Exp Cell Res 277:201-209

89. Collins K (2008) Physiological assembly and activity of human telomerase complexes. Mech Ageing Dev 129:91-98

90. McEachern MJ, Krauskopf A, Blackburn EH (2000) Telomeres and their control. Annu Rev Genet 34:331-358

91. Taggart AK, Teng SC, Zakian VA (2002) Estlp as a cell cycleregulated activator of telomere-bound telomerase. Science 297:1023-1026

92. Bachand F, Boisvert FM, Côté J et al (2002) The product of the survival of motor neuron (SMN) gene is a human telomeraseassociated protein. Mol Biol Cell 13:3192-3202

93. Tomlinson RL, Abreu EB, Ziegler T et al (2008) Telomerase reverse transcriptase is required for the localization of telomerase RNA to Cajal bodies and telomeres in human cancer cells. Mol Biol Cell 19:3793-3800 
94. Hamma T, Ferré-D'Amaré AR (2010) The box H/ACA ribonucleoprotein complex: interplay of the RNA and protein structures in post-transcriptional RNA modification. J Biol Chem 285:805-809

95. Venteicher AS, Meng Z, Mason PJ et al (2008) Identification of ATPases pontin and reptin as telomerase components essential for holoenzyme assembly. Cell 132:945-957

96. Collins K, Mitchell JR (2002) Telomerase in the human organism. Oncogene 21:564-579

97. Alves D, Li H, Codrington R et al (2008) Single-molecule analysis of human telomerase monomer. Nat Chem Biol $4: 287-289$

98. Fiset S, Chabot B (2001) hnRNP A1 may interact simultaneously with telomeric DNA and the human telomerase RNA in vitro. Nucleic Acids Res 29:2268-2275

99. Venteicher AS, Artandi SE (2009) TCAB1: driving telomerase to Cajal bodies. Cell Cycle 8:1329-1331

100. de Lange $T$ (2005) Shelterin: the protein complex that shapes and safeguards human telomeres. Genes Dev 19:2100-2110

101. Blasco MA (2007) The epigenetic regulation of mammalian telomeres. Nat Rev Genet 8:299-309

102. Liu WJ, Zhang YW, Zhang ZX, Ding J (2004) Alternative splicing of human telomerase reverse transcriptase may not be involved in telomerase regulation during all-trans-retinoic acidinduced HL-60 cell differentiation. J Pharmacol Sci 96:106-114

103. Ye JZ, Donigian JR, Van Overbeek M et al (2004) TIN2 binds TRF1 and TRF2 simultaneously and stabilizes the TRF2 complex on telomeres. J Biol Chem 279:47264-47271

104. Wang F, Podell ER, Zaug AJ et al (2007) The POT1-TPP1 telomere complex is a telomerase processivity factor. Nature 445:506-510

105. Xin H, Liu D, Wan M et al (2007) TPP1 is a homologue of ciliate TEBP- $\beta$ and interacts with POT1 to recruit telomerase. Nature 445:559-562

106. Luke B, Lingner J (2009) TERRA: telomeric repeat-containing RNA. EMBO J 28:2503-2510

107. Nandakumar J, Podell ER, Cech TR (2010) How telomeric protein POT1 avoids RNA to achieve specificity for singlestranded DNA. Proc Natl Acad Sci USA 107:651-656

108. Takai KK, Hooper S, Blackwood S et al (2010) In vivo stoichiometry of shelterin components. J Biol Chem 285:1457-1467

109. Smogorzewska A, Van Steensel B, Bianchi A et al (2000) Control of human telomere length by TRF1 and TRF2. Mol Cell Biol 20:1659-1668

110. Shore D, Bianchi A (2009) Telomere length regulation: coupling DNA end processing to feedback regulation of telomerase. EMBO J 28:2309-2322

111. Ancelin K, Brunori M, Bauwens S et al (2002) Targeting assay to study the cis functions of human telomeric proteins: evidence for inhibition of telomerase by TRF1and for activation of telomere degradation by TRF2. Mol Cell Biol 22:3474-3487
112. Smogorzewska A, de Lange T (2004) Regulation of telomerase by telomeric proteins. Annu Rev Biochem 73:177-208

113. O'Connor MS, Safari A, Liu D et al (2004) The human Rap1 protein complex and modulation of telomere length. J Biol Chem 279:28585-28591

114. Chai W, Ford LP, Lenertz L et al (2002) Human Ku70/80 associates physically with telomerase through interaction with hTERT. J Biol Chem 277:47242-47247

115. Ting NS, Yu Y, Pohorelic B et al (2005) Human Ku70/80 interacts directly with hTR, the RNA component of human telomerase. Nucleic Acids Res 33:2090-2098

116. Nakano M, Kakiuchi Y, Shimada Y et al (2009) MOV10 as a novel telomerase-associated protein. Biochem Biophys Res Commun 388:328-332

117. Uziel O, Fenig E, Nordenberg J et al (2005) Imatinib mesylate (Gleevec) downregulates telomerase activity and inhibits proliferation in telomerase-expressing cell lines. $\mathrm{Br} \mathrm{J}$ Cancer 92:1881-1891

118. Zhou C, Bae-Jump VL, Whang YE et al (2006) The PTEN tumor suppressor inhibits telomerase activity in endometrial cancer cells by decreasing hTERT mRNA levels. Gynecol Oncol 101:305-310

119. Kunisada M, Budiyanto A, Bito T et al (2005) Retinoic acid suppresses telomerase activity in HSC-1 human cutaneous squamous cell carcinoma. Br J Dermatol 152:435-443

120. Kimura A, Ohmichi M, Kawagoe J et al (2004) Induction of hTERT expression and phosphorylation by estrogen via Akt cascade in human ovarian cancer cell lines. Oncogene 23:4505-4515

121. Choi SH, Lyu SY, Park WB (2004) Mistletoe lectin induces apoptosis and telomerase inhibition in human A253 cancer cells through dephosphorylation of Akt. Arch Pharm Res 27:68-76

122. Wetterau LA, Francis MJ, Ma L, Cohen P (2003) Insulin-like growth factor I stimulates telomerase activity in prostate cancer cells. J Clin Endocrinol Metab 88:3354-3359

123. Kawauchi K, Ihjima K, Yamada O (2005) IL-2 increases human telomerase reverse transcriptase activity transcriptionally and posttranslationally through phosphatidylinositol $3^{\prime}$-kinase/Akt, heat shock protein 90 , and mammalian target of rapamycin in transformed NK cells. J Immunol 174:5261-5269

124. Minamino T, Mitsialis SA, Kourembanas S (2001) Hypoxia extends the life span of vascular smooth muscle cells through telomerase activation. Mol Cell Biol 21:3336-3342

125. Ram R, Uziel O, Eldan O et al (2009) Ionizing radiation upregulates telomerase activity in cancer cell lines by post-translational mechanism via ras/phosphatidylinositol 3-kinase/Akt pathway. Clin Cancer Res 15:914-923

126. Alfonso-De Matte MY, Cheng JQ, Kruk PA (2001) Ultraviolet irradiation- and dimethyl sulfoxide-induced telomerase activity in ovarian epithelial cell lines. Exp Cell Res 267:13-27 